\title{
Study on Crystalline Volume Fraction and Activation Energy for Silicon Thin Film Prepared by VHF-PECVD
}

\author{
Qingdong Chen ${ }^{1, a}, J_{u n p i n g ~ W a n g}{ }^{1, b^{-}}$ \\ ${ }^{1}$ Faculty of Aerospace Engineering ,Binzhou University, Binzhou 256603, China \\ achenqingdong-88@163.com, ${ }^{\mathrm{b}}$ wangjunping-99@163.com
}

\begin{abstract}
Key words:VHF-PECVD; microcrystalline silicon; activation energy; crystalline volume fraction Abstract: Intrinsic microcrystalline silicon thin film were prepared by VHF-PECVD, the activation energy of thin film were measured by activation energy testing equipment. The activation energy of samples with different crystalline volume fraction were studied. The results showed that: the activation energy of samples deposited at amorphous/microcrystalline transition zone decreases crystalline volume fraction increasing.
\end{abstract}

\section{Introduction}

At present, at home and abroad are very concerned about the study of microcrystalline silicon thin film solar cells, mainly concentrated in the United Solar of United States [1], Kaneka Corporation of Japan [2], Julich photovoltaic research institute of Germany [3], Utrecht University of Netherlands [4], IMT Institute of Swiss [5] and Optoelectronic Thin Film Device and Technology Research Institute of Nankai University in china [6].The very high frequency plasma chemical vapor deposition (VHF-PECVD) technique can be well compatible with conventional RF-PECVD technique, so microcrystalline silicon film preparation is widely concerned and has made great progress in the research.

The dark conductivity and activation energy $E_{A}$ depend strongly on a few ppm order of magnitude dopant, many laboratories found that non doped microcrystalline silicon film is similar with $\mathrm{N}$ type film, the activation energy is about $0.4 \mathrm{eV}$, the dark conductivity is enhanced to $10^{-6} \mathrm{~s} / \mathrm{cm}$, which is not suitable for solar cell. $\mathrm{N}$ type feature is most likely due to oxygen donor in grain boundaries, plays a role of n-type doping, leakage current is produced by oxygen donor along the columnar structure, so reducing the microcrystalline open circuit voltage and fill factor of silicon solar cell.

In this paper, the activation energy of microcrystalline silicon thin film prepared by VHFPECVD were studied, the samples were studied by The United States KEITHLEY6517A multimeter / high resistance test instrument.

\section{Experimental}

Figure 1 shows the testing equipment of activation energy, it is a sealed vacuum device made of stainless steel, there is a quartz window on top of the equipment, a light source can add above it, so the photoconductivity of silicon film can be measured. On the upper flange plate is equipped

Corresponding author.

E-mail address:wangjunping-99@163.com (J. Wang) 
with air bleed valve. The sample is measured on the copperplate, copper electrode can change measuring distance by adjusting the electrode pillars. The heating pipe is arranged in two sides of copper plate, Electric wire is wound on heating pipe. The cooling block is located below copper plate with cooling water for cooling. The copper plate is located on the pillar of PTFE, one is for the electric insulation, and the second is for heat insulation. Steel walls and lower flange plate is sealed by $\mathrm{O}$ ring. There are pumping holes, wire outlet and cooling water pipe outlet under the lower flange plate. The equipment is vacuum pumped by mechanical pump, the temperature is controlled by temperature control instrument, the range from room temperature to $200^{\circ} \mathrm{C}$. The data acquisition system of the equipment isthe United States KEITHLEY6517A multimeter/ high resistance test instrument, test voltage range from $0 \mathrm{~V}$ to $400 \mathrm{~V}$, test current range from $20 \mathrm{pA}$ to $200 \mu \mathrm{A}$, test resistance can reach up to $200 \mathrm{~T} \Omega$.

All the samples were prepared by VHF-PECVD, depositing frequency: $75 \mathrm{MHz}$. The samples were analyzed by Raman spectroscopy with a Renishaw MR-2000 Raman spectrometer.The crystallization rate of materials is estimated by integral intensity ratio $X_{C}, X_{C}=\left(I_{510}+I_{520}\right)\left(I_{510}+I_{520}\right.$ $\left.+I_{480}\right)$. In this equation, $I_{520}$ is crystalline silicon characteristic peak intensity, $I_{480}$ is amorphous crystalline silicon characteristic peak intensity, $I_{510}$ is generally believed to be caused by small grain scattering.

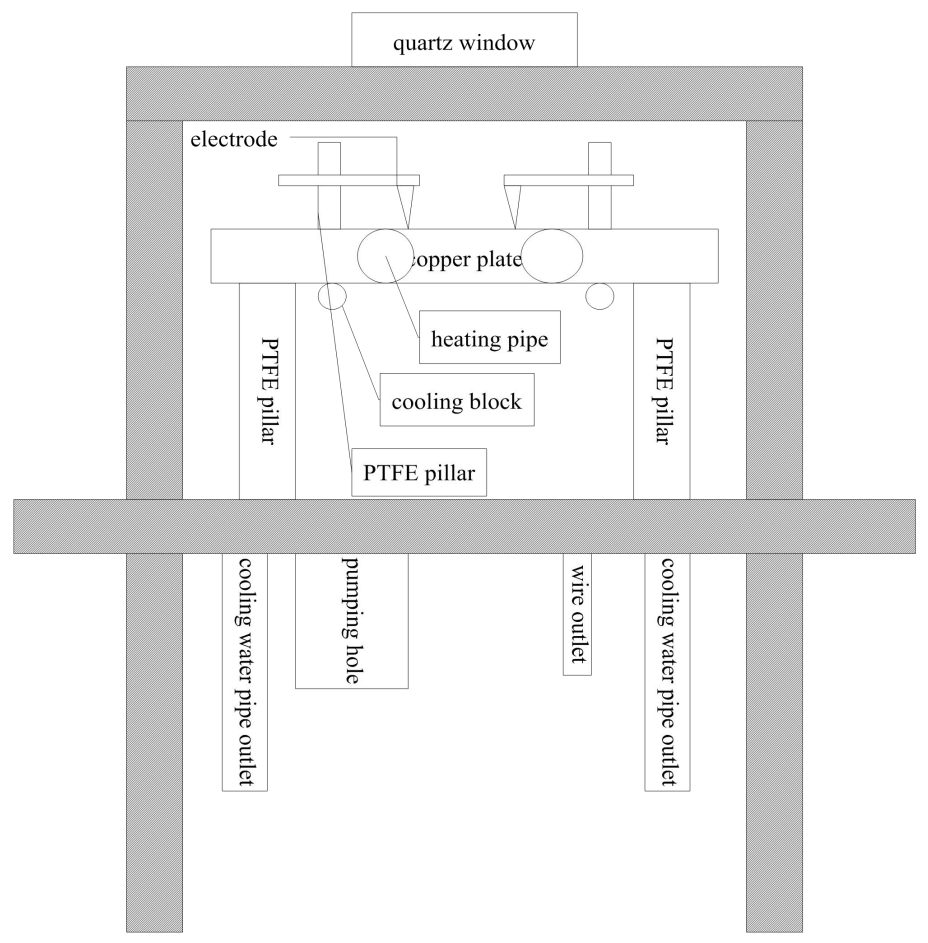

Fig. 1 The testing equipment of activation energy

\section{Results and discussion}

Activation energy study of different crystalline volume fraction samples

The intrinsic samples were deposited at $\mathrm{SiH}_{4}$ concentration 3\%、4\%, table1、2shows deposition condition, figure $2 、 3$ shows Raman spectrum of samples, it shows that the samples are in the amorphous and microcrystalline phase transition domain. Figure4 5 shows the curve of $\sigma-1000 / \mathrm{T}$ of samples, it was found that: the conductivity changes greater when the activation energy is higher. Forthe sample whose activation energy is $0.585 \mathrm{eV}$, the conductance changes with 
three orders of magnitude. The activation energy decreases with increasing crystalline volume fraction.

Due to amorphous silicon band gap is bigger than crystalline silicon, the band gap of amorphous silicon is $1.8 \mathrm{eV}$, the band gap of crystalline silicon is $1.2 \mathrm{eV}$, in the amorphous / microcrystalline phase transition zone, the higher the crystalline volume fraction, the more crystalline silicon components, the less amorphous components, so the activation energy decreases with increasing crystalline volume fraction. Based on S. Kirkpatrick Effective Medium Approximation theory [7], a kind of film consists of amorphous disorderly network and crystal particles two phase structure, when the crystalline volume fraction is higher, the carrier transition mainly between crystal particles embedded in the amorphous network, so the activation energy required for the transition of charge carriers is greatly reduced, and the carrier mean free path is greatly prolonged.

Table 1: The deposition condition and crystalline volume fraction of samples

\begin{tabular}{llllllll}
\hline sample & $\begin{array}{c}\mathrm{SiH}_{4} \\
\text { concentration }\end{array}$ & $\begin{array}{l}\text { temperature } \\
\left({ }^{\circ} \mathrm{C}\right)\end{array}$ & $\begin{array}{l}\text { pressure } \\
(\mathrm{Pa})\end{array}$ & $\begin{array}{l}\text { power } \\
(\mathrm{w})\end{array}$ & substrate & $\begin{array}{l}\text { thickness } \\
(\mathrm{nm})\end{array}$ & $\begin{array}{l}\text { crystalline } \\
\text { volume }(\%)\end{array}$ \\
\hline 1 & $3 \%$ & 200 & 300 & 113 & glass & 457.2 & 15.2 \\
2 & $3 \%$ & 200 & 300 & 91 & glass & 373 & 23.3 \\
3 & $3 \%$ & 200 & 300 & 113 & quartz & 309.6 & 41.8 \\
4 & $3 \%$ & 200 & 300 & 91 & quartz & 423 & 47.8 \\
\hline
\end{tabular}

Table 2: The deposition condition and crystalline volume fraction of samples

\begin{tabular}{ccccccc}
\hline sample & $\begin{array}{c}\mathrm{SiH}_{4} \\
\text { concentration }\end{array}$ & $\begin{array}{c}\text { temperature } \\
\left({ }^{\circ} \mathrm{C}{ }^{\circ} \mathrm{C}\right)\end{array}$ & $\begin{array}{l}\text { pressure } \\
(\mathrm{Pa})\end{array}$ & $\begin{array}{l}\text { power } \\
(\mathrm{w})\end{array}$ & $\begin{array}{l}\text { thickness } \\
(\mathrm{nm})\end{array}$ & $\begin{array}{l}\text { crystalline } \\
\text { volume }(\%)\end{array}$ \\
\hline 1 & $4 \%$ & 200 & 250 & 120 & 131 & 0 \\
2 & $4 \%$ & 200 & 200 & 120 & 391.95 & 18.4 \\
3 & $4 \%$ & 220 & 300 & 140 & 630 & 36.4 \\
4 & $4 \%$ & 225 & 260 & 125 & 830.76 & 58.3 \\
\hline
\end{tabular}

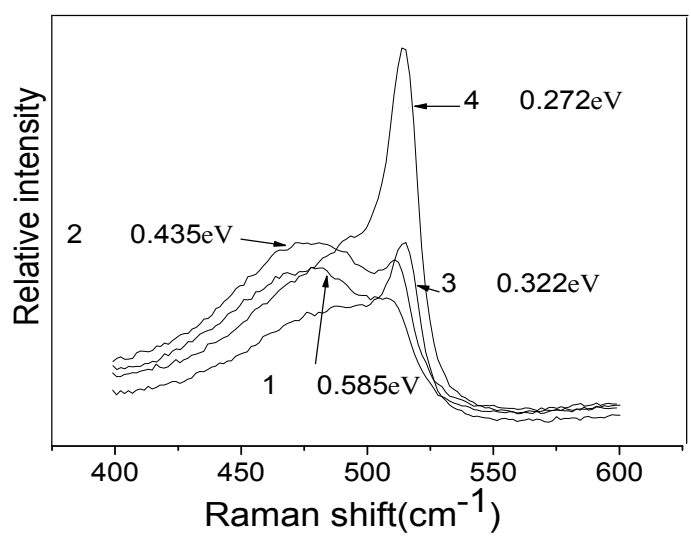

Fig.2:Raman spectra of samples at $\mathrm{SiH}_{4}$ concentration $3 \%$

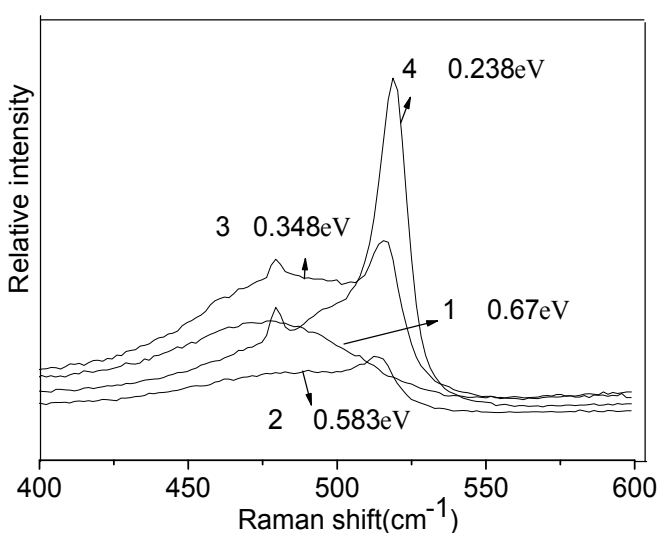

Fig.3:Raman spectra of samples at $\mathrm{SiH}_{4}$ concentration $4 \%$ 


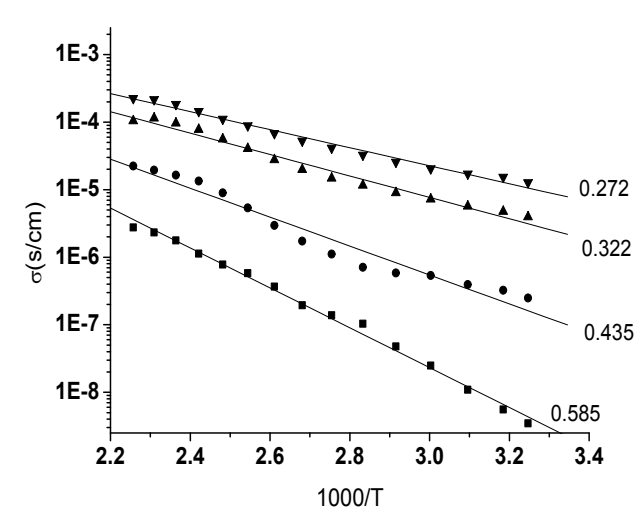

Fig.4 The curve of $\sigma-1000 / \mathrm{T}$ of samples at $\mathrm{SiH}_{4}$

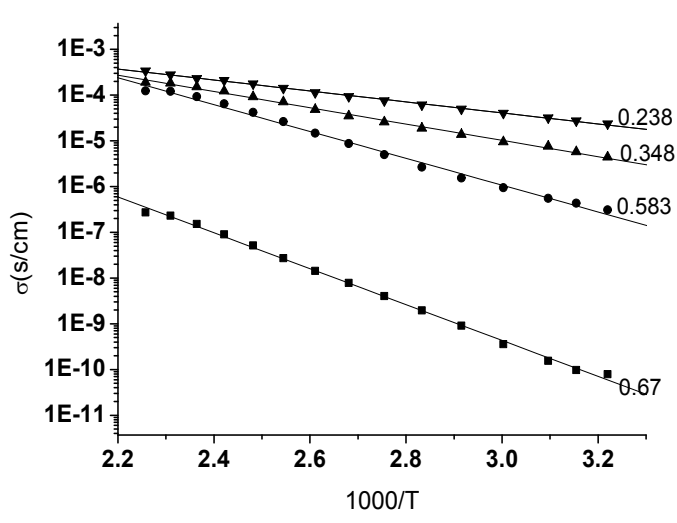

Fig. 5 The curve of $\sigma-1000 / \mathrm{T}$ of samples at

$\mathrm{SiH}_{4}$ concentration $3 \%$

concentration $4 \%$

However, the activation energy values of material are smaller than the actual intrinsic microcrystalline silicon solar cells (more than $0.5 \mathrm{eV}[8]$ ), this may be the effect of oxygen ion in the material. Because it usually think that there are many grain boundaries in microcrystalline silicon materials, which non densely than the crystal silicon, in the growth process of material will enter the oxygens ion. When entering trace oxygen impurity, the intrinsic silicon Fermi band going up, thin films exhibit a weak n type, the specific performance is that the dark conductivity rises and the activation energy falls. So the value of the activation energy can directly reflect the microcrystalline silicon thin film oxygen contamination level.

\section{Conclusions}

The activation energy of intrinsic microcrystalline silicon thin film which is high speed deposited by VHF-PECVD were studied by KEITHLEY6517A multimeter / high resistance test instrument. It was found that: the prepared samples were in amorphous/microcrystalline transition zone, the activation energy were decreased by increasing crystalline volume fraction. the activation energy values of material are smaller than the actual intrinsic microcrystalline silicon solar cells, this may be the effect of oxygen ion in the material.

\section{Acknowledgement}

This work was supported by National Natural Science Foundation(41401384); The University Science and Technology Project of Shandong Province (J17KB127);Binzhou City Science and Technology Development Plans (2014ZC0307) ; Binzhou City Science and Technology Development Plans(2015ZC0210); The Doctoral Scientific Research Foundation of Binzhou University (2014Y10); Binzhou University Research Fund Project (BZXYG1513)and Binzhou University Research Fund Project (BZXYG1706).

\section{References}

[1]Yan B J,Yue G Z,Yang J,et al..Mater Res Soc Symp Proc,2003:762

[2]Yamamoto K,Nakajima A,Yoshimi M, et al..Solar Energy, 2004,77:939

[3]Klein S,Repmann T, Brammer T .Solar Energy,2004,77:893

[4]Van Veen M K, Vander Werf C H M,Rath J K,et al.Thin Solid Films,2003,430:216 
[5]Shah A,Vallat-Sauvain E,Torres P,et al.Mater Sci Eng B,2000,69/70:219

[6]Prasad K, Finger F,Dubail S ,et al .J Non-CrystSolids ,1991, 137/138: 681

[7]S.Kirkpatrick.Reviews of modern physics, 1973,45 (4):574

[8]Shah A,Meier M, VallatSauvain E,et,al.Thin solid Films,2002,403-404.179. 